\title{
Effect of Non-Rubber Constituents on Guayule and Hevea Rubber Intrinsic Properties
}

\author{
Shirin M.A. Monadjemi ${ }^{\mathrm{a}}$, Colleen M. McMahan ${ }^{\mathrm{b}}$ and Katrina Cornish ${ }^{\mathrm{a},{ }^{*}}$ \\ ${ }^{a}$ Ohio Agricultural Research and Development Center, Department of Food, Agricultural and Biological \\ Engineering, The Ohio State University, Wooster, OH 44691, USA \\ ${ }^{b}$ United States Department of Agriculture, Agricultural Research Service, Western Regional Research \\ Laboratory, Albany, CA 94710, USA
}

\begin{abstract}
To meet the increasing demand for natural rubber (NR), currently sourced from the tropical rubber tree Hevea brasiliensis, and address price volatility and steadily increasing labor costs, alternate rubber-producing species are in commercial development. One of these, guayule (Parthenium argentatum), has emerged on the market as a commercial source of high quality rubber. Non-rubber constituents play an important role in the physical properties of NR products. The intrinsic composition of the two NR materials differs and these differences may be a principal cause of the performance differences between them.

We have compared the effect of non-rubber constituents, such as protein, lipids, resin and rubber particle membranes. Firstly, a film casting method was developed to obtain rubber films with a uniform thickness. Secondly, the glass transition temperature of different rubbers was determined by dynamic mechanical analysis, and tensile properties were tested for uncompounded materials. Guayule natural rubber (GNR), from which most of the membranes were removed while in latex form (MRGNR) was found to have higher intrinsic strength than GNR or gel-free NR (FNR). An acetone extraction was performed to quantify the resin and free lipids in the rubber samples.
\end{abstract}

Keywords: Guayule, Hevea, natural rubber, protein, resin.

\section{INTRODUCTION}

Natural rubber (NR) has outstanding tensile properties and good crack growth resistance, which originate from its ability to crystallize upon elongation. This crystallizability, known as strain-induced crystallization, has been attributed to non-rubber constituents present in NR, the regularity of isoprene units in the cis-1,4 configuration, and the naturally occurring network $[1,2]$. The structure of NR consists of long polymer chains composed, in order, of an $\alpha$ terminus, $\sim 5,000$ or more cis-1,4 isoprene units followed by two trans-1,4 isoprene units and an $\omega$ terminus. Each terminal group can link to non-rubber constituents. It has been proposed that the a-terminus links to phospholipids and the $\omega$-terminus to proteins [3]. These non-rubber components account for only $6 \%$ of the NR composition [4] but contribute essentially to the formation of a natural network. It was also demonstrated that divalent cations, such as calcium and magnesium ions are involved in the network linkages [5]. On the other hand, synthetic polyisoprene rubber (IR) which differs essentially from NR by the absence of non-rubber components, a lower level of branched polymer chains and lower cis-1,4

*Address correspondence to this author at the Ohio Agricultural Research and Development Center, Department of Food, Agricultural and Biological Engineering, The Ohio State University, Wooster, OH 44691, USA

Tel: (330) 263-3982; E-mail: cornish.19@osu.edu polyisoprene conformation, also lacks green strength $[6,7]$. Natural rubber obtained from Parthenium argentatum, (guayule), likewise exhibits low green strength and low strain-induced crystallizability. However, it does contain natural non-rubber constituents and is highly stereoregular, similar to Hevea NR [7].

In this work, we aimed to explore the influence of the non-rubber components on the mechanical properties of unvulcanized guayule rubber, which is an alternative to natural rubber (from Hevea brasiliensis). Both species produce rubber particles as aqueous emulsions, the particles consisting of a homogeneous rubber core, and entirely covered by a monolayer membrane composed of lipids, sterols and proteins [8]. Therefore, membrane removed rubber particles, deproteinized rubber, and acetone extracted rubber were prepared and were analyzed by uniaxial deformation tests and were compared with the performance of the raw rubbers.

\section{MATERIALS AND METHODS}

\section{Materials}

Hevea (NR) was standard Thai rubber (STR5L) and the generous gift of Verve, Inc. (Providence, RI). Low protein NRL (LPNR) was commercially available as Vytex $^{\mathrm{TM}}$ latex (Vystar,GA, USA). Membrane removed guayule natural rubber (MRGNR) and membrane 
removed Hevea natural rubber (MRNR) were kindly prepared by Ms. Eun Hyang Han and Dr. Joshua J. Blakeslee by a proprietary method. MRNR was prepared from Centex HA latex (Centrotrade, Chesapeake, VA, USA), MRGNR was prepared from freshly extracted guayule latex. The efficient membrane removal was confirmed by the nitrogen content analysis. HPLC grade chloroform was purchased from Fisher Scientific (Pittsburgh, PA, USA). Alcalase from Bacillus licheniformis was purchased from Sigma Aldrich (St. Louis, MO, USA).

\section{Preparation of Rubber Samples}

All rubber samples described in this section are listed and summarized in Table 1.

1. Preparation of gel-free natural rubber (FNR) Gel-free NR (FNR) was obtained by dissolving NR in HPLC grade hexane (Fisher Chemicals, Fairlawn, $\mathrm{NJ}$ ) for $3 \mathrm{~h}$ using a Corning Stir Plate at $280 \mathrm{rpm}$. The mixture was sieved through a 1 $\mathrm{mm}$ sieve and the gel fraction was discarded. The FNR was obtained by evaporating the hexane from the rubber solution.
2. Preparation of deproteinized guayule natural rubber (DPGNR) - The method was adapted from a published method [9]. GNRL (Guayule natural rubber latex) with $55 \%$ dry rubber content (stabilized with $0.3 \% \quad \mathrm{NH}_{4} \mathrm{OH}, 0.09 \%$ sodium dodecyl benzene sulfonate, $0.02 \%$ potassium laurate, $\mathrm{pH} 10$ ) was used for the preparation of DPGNR by the combination of enzyme treatment and centrifugation methods. First, the GNR latex was diluted to $30 \%$ dry rubber content, centrifuged 10 minutes at $10,000 \times g$ and the rubber phase was diluted in deionized water. This step was repeated twice and the $\mathrm{pH}$ was adjusted to 7-8 with acetic acid. Then $0.2 \mathrm{phr}$ alcalase $(0.0044 \mathrm{U} / \mathrm{g}$ of DRC) was added and the mixture was incubated at $37^{\circ} \mathrm{C}$ for $48 \mathrm{~h}$. The latex was centrifuged at $15,000 \times \mathrm{g}$ for 15 minutes. The aqueous layer was removed and replaced by an equal volume of distilled water and homogeneously remixed. The solution was centrifuged a second time at $15,000 \times \mathrm{g}$ for 15 minutes. The upper rubber layer (DPGNR) was dried at $50^{\circ} \mathrm{C}$ in a drying oven overnight.

3. Acetone extracted rubber - The acetone extracted $(A E)$ rubber was prepared by washing

Table 1: Description of the Rubber Samples Used in this Study

\begin{tabular}{|c|c|c|}
\hline Abbreviation & Full name & Description/Purpose \\
\hline NR & Natural rubber from Hevea & $\begin{array}{l}\text { Hevea NR control which contains soluble protein, membrane protein and } \\
\text { lipid, and gel }\end{array}$ \\
\hline FNR & Gel-Free NR & $\begin{array}{c}\text { The soluble fraction of Hevea NR which should be free of lipids and } \\
\text { solubleproteins }\end{array}$ \\
\hline MRNR & Membrane-removed NR & $\begin{array}{l}\text { The membrane bound protein and lipids are removed but the peptide and } \\
\text { lipid linkages in the Hevea NR gel fraction remain }\end{array}$ \\
\hline LPNR & Low protein NR (Vytex $\left.{ }^{\mathrm{TM}}\right)$ & $\begin{array}{l}\text { Intact Hevea NR rubber particles but without soluble proteins, contains } \\
\text { membrane lipids }\end{array}$ \\
\hline GNR & Natural rubber from guayule & $\begin{array}{l}\text { Guayule NR control which contains membrane bound protein }(\sim 1 \% \text { of the } \\
\text { total protein in NR) and lipid, and terpene resin }\end{array}$ \\
\hline DPGNR & Deproteinized (protein free) GNR & $\begin{array}{c}\text { GNR treated with protease then washed to remove all proteins and peptide } \\
\text { fragments and residual protease }\end{array}$ \\
\hline AE-NR & Acetone extracted NR & $\begin{array}{c}\text { Hevea NR from which low molecular weight acetone-soluble components, } \\
\text { including some lipids, have been removed but which retains gel and } \\
\text { proteins }\end{array}$ \\
\hline AE-MRGNR & $\begin{array}{l}\text { Acetone extracted membrane-removed } \\
\text { GNR }\end{array}$ & Pure GNR polymer \\
\hline AE-FNR & Acetone extracted gel-free NR & $\begin{array}{l}\text { The soluble fraction of Hevea NR from which low molecular weight acetone- } \\
\text { soluble componentshave been removed }\end{array}$ \\
\hline AE-GNR & Acetone extracted GNR & $\begin{array}{c}\text { GNR from which the resin and some lipids have been removed but which } \\
\text { retains membrane bound protein }\end{array}$ \\
\hline
\end{tabular}


$4.5 \mathrm{~g}$ of rubber cut into $1 \mathrm{~mm}^{3}$ pieces, with $30 \mathrm{ml}$ acetone for $48 \mathrm{~h}$. The washing was repeated twice. The washed rubber was separated from the solvent and allowed to dry overnight at ambient temperature. The acetone was removed from the extract by rotatory evaporation and the solid residue was quantified.

\section{Rubber Film Casting}

The dried rubber samples were cut approximately into $1 \mathrm{~mm}^{3}$ pieces, and $4 \mathrm{~g}$ were dissolved in $60 \mathrm{ml}$ chloroform. The mixture was shaken for $24 \mathrm{~h}$ and cast in glass petri dishes $(160 \times 30 \mathrm{~mm})$. The thickness of the films obtained was $0.6 \pm 0.1 \mathrm{~mm}$.

\section{Physical and Chemical Characterization}

The molecular weight distributions of the polymers were determined by Gel Permeation Chromatography. Approximately $3 \mathrm{mg}$ of dried rubber sample were solubilized in $3 \mathrm{ml}$ tetrahydrofuran (THF) overnight with gentle shaking (Multi-Purpose Rotator, Thermo Scientific). The rubber solution was syringe-filtered through a $1.6 \mu \mathrm{m}$ glass microfiber GF/A filter (Whatman GE Healthcare) then injected into a Hewlett-Packard 1100 series HPLC $(1.0 \mathrm{~mL} / \mathrm{min}$ flowrate, $50 \mu \mathrm{l}$ injection volume, THF continuous phase) and size exclusion separated by two Agilent PL gel $10 \mu \mathrm{m}$ Mixed-B columns in series $\left(35^{\circ} \mathrm{C}\right)$ coupled to 1$)$ multi-angle laser light scattering (DAWN Heleos-II, Wyatt Technology, Santa Barbara, CA), 2) Refractive Index (Agilent 1260 Infinity, dn/dc=0.129), and 3) UV (HP 1100 series at $254 \mathrm{~nm}$ ) detectors. Fourier transform infrared (FTIR) spectra were recorded with a Spectrum Two spectrophotometer (Perkin Elmer) equipped with a diamond crystal. The rubber film spectra were obtained in the range of $4000-450 \mathrm{~cm}^{-1}$ in the attenuated total reflectance (ATR) mode using 10 scans acquired at a resolution of $4 \mathrm{~cm}^{-1}$.

\section{Gel Content Measurement}

Determination of gel content was carried out in accordance with ISO/TC 45/SC 3N 1166. However, for guayule rubber, the sample amount had to be increased to $0.3 \mathrm{~g}$ due to its lower gel content.

\section{Elemental Composition}

Protein content was determined from the nitrogen content ( $\% \mathrm{~N})$ using the Dumas method as described in the AOAC Official methods of analysis [10]. The basis of the technique is the conversion of all nitrogen forms to nitrogen oxides by combustion following by the reduction of these forms to nitrogen gas $\left(\mathrm{N}_{2}\right)$. About $300 \mathrm{mg}$ of rubber was sampled, oven dried in a clean metal crucible then weighed accurately. The sample was then analyzed by a vario MAX carbon-nitrogen analyzer (Elementar Americas, $\mathrm{NJ}$ ). The protein content was estimated by multiplying the $\mathrm{N} \%$ by 6.25 . The rubber elemental composition was performed by digestion of a $1 \mathrm{~g}$ sample with concentrated hydrochloric acid and nitric acid followed by an inductively coupled plasma spectrophotometer analysis $[11,12]$ (Prodigy Dual View, Teledyne technology, NH).

\section{Mechanical Properties}

Mechanical properties of the samples were evaluated by uniaxial stretching. Cast films (thickness $0.6 \mathrm{~mm}$ ) were cut into dumbbell samples using ASTM D412 Die C (see Figure 2 of ASTMD412 for complete dimensions). In brief, the length of the narrow section of the dumbbell is $33+2 \mathrm{~mm}$, the width at the center point is $14 \mathrm{~mm} \pm 1$, and the total length is $128 \mathrm{~mm}$. The tensile mechanical properties were measured at ambient temperature using a tensiometer (Model 3366, Instron, Norwood, MA) at a constant strain rate $(500$ $\mathrm{mm} / \mathrm{min}$ ). Six replicates were carried out for each sample and the results were averaged. Young's modulus, the manifestation of material stiffness, was evaluated from the initial linear part of the stress-strain curves (Hooke's region). The ultimate tensile strength (UTS) was defined as either a maximum distinct or a region of strong curvature approaching a zero slope in the stress-strain curve. The glass transition was determined by dynamic mechanical analysis (Q800, TA instruments) with oscillation amplitude of $50 \mu \mathrm{m}$, a static force of $0.01 \mathrm{~N}$, a force track of $125 \%$ and a temperature ramp of $5^{\circ} \mathrm{C} / \mathrm{min}$.

\section{RESULTS AND DISCUSSION}

Acetone extraction of rubber samples solubilizes low molecular weight organic constituents including resins and neutral lipids which are not believed to affect the formation of branch points $[4,13]$. The extracts were quantified for each rubber type (Table 2). The acetone extract of NR was $2.9 \%$ which is close to the value reported in the literature [13]. In FNR, which is the soluble fraction of NR in hexane, a higher percent of extractable was measured. This is because hexane extracts the lower molecular weight components of the NR including resin and lipids. GNR was found to have up to $14 \%$ of acetone extractable content which could explain the softness of this material. 
Table 2: Quantification of the Acetone Soluble Extracts. Values are Average of Two Replicates and all Fall within a $10 \%$ Error Margin

\begin{tabular}{|c|c|}
\hline Rubber type & Acetone soluble extract, $\%$ \\
\hline \hline NR & 2.9 \\
\hline MRNR & 2 \\
\hline FNR & 6.5 \\
\hline GNR & 14 \\
\hline MRGNR & 8 \\
\hline
\end{tabular}

The rubber samples, MRNR and MRGNR, both had less acetone soluble material than NR and GNR, respectively, since the membrane removal process discards some of the free lipids. However, the acetone extracts were not zero, as might be expected. The overestimation is due to the fact that the membrane removal process is not $100 \%$ efficient. The membrane removal process could leave residual rubber particle membrane fragments in the rubber. Another possibility is the coextraction of low molecular weight polyisoprene released in the media after the membrane removal. It should be noted that the acetone extracts contained variable resin amounts, the viscous liquid left after the acetone evaporation.

\section{Mechanical Properties}

Nonrubber constituents, such as phospholipids and proteins, have been reported to participate actively in the natural occurring network of the rubbers. In unvulcanized natural rubber, these confer to the material the green strength property which is known as strain-induced crystallization (SIC). This phenomenon, referring to the upturn in the stress-strain plot, is characterized by the formation of crystalline domains that act as cross-link junctions in the rubber matrix [15, 16, 19]. The plot of NR and FNR under uniaxial extension (Figure 1), indicates that raw NR rubber has the highest green strength and a high elongation at break. Its curve shows an upturn at high strain which indicates that it undergoes strain-induced crystallization. On the other hand, raw FNR shows no upturn and breaks at a strain of $220 \%$. Both NR and FNR have a nitrogen content close to $0.4 \%$ (Table 5 ), therefore the weaker mechanical properties of FNR cannot be assigned to the protein contents alone. NR may have intact protein-polymer linkages, as indicated by higher gel $(50 \%)$ than FNR $(33 \%)$. These results can also be attributed to the differences in the molecular weight and the rubber composition. The average molecular weight of the NR and the FNR are
$1.4 \times 10^{6} \mathrm{~g} \mathrm{~mol}^{-1}$ and $1.0 \times 10^{6} \mathrm{~g} \mathrm{~mol}^{-1}$, respectively (Table 4). Therefore, the long polymer chains of Hevea rubber can cause entanglement and induce SIC $[5,20]$.

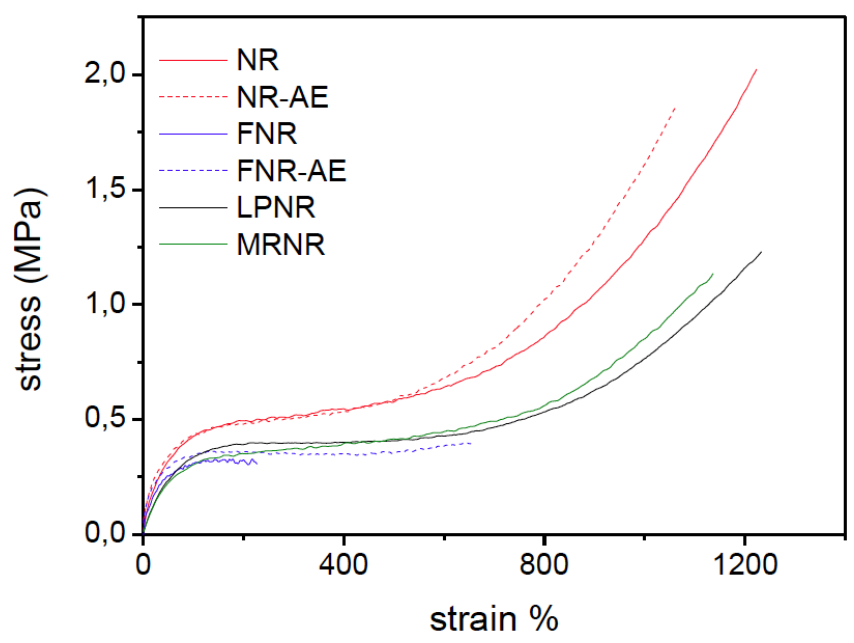

Figure 1: Green strength profile of Hevea rubber (NR), gelfree Hevea rubber (FNR), low protein Hevea rubber (LPNR) and membrane removed Hevea rubber (MRNR). Raw rubber (solid line) and acetone extracted rubbers (AE, dashed lines). Each curve is the mean of 4 replicates.

Additionally, the functionalized chains ends of NR, its high protein content (see $\mathrm{N} \%$ in Table 4) and the presence of divalent cations such as calcium and magnesium ions promote network formation and make permanent entanglements that can induce SIC $[5,20]$. The lower protein content in FNR is due to its method of preparation. The hexane solubilization step for the preparation of FNR discards most of the soluble proteins $[23,24]$.

It has been reported that acetone extraction does not cause an alteration of the polymer chains since no significant change in the molecular weight is observed after acetone treatment of deproteinized natural rubber (DPNR) [5]. After acetone extraction, NR films appeared to be stiffer than the raw material, having a higher green strength between 600 and $1100 \%$ elongation (Figure 1). The mechanical properties of FNR also changed; the elongation at break and ultimate tensile strength were improved to such an extent that a starting upturn could be visible in the stress-strain plot (Figure 1). Our results suggest low molecular weight components such as free lipids can diminish polymer chain crystallization. In fact, free lipids are plasticizers that space between the polymer chains and reduce the polymer intermolecular interactions. This in turn increases the molecular mobility of the chains, and thus decreases the cohesive energy [17, 18]. The removal of plasticizers by the acetone extraction treatment could therefore explain the 
increase of the Young's modulus observed in our results. GNR was found to contain up to $14 \%$ of acetone extractable content. Thus the $\mathrm{Ym}$ increase after the acetone extraction is more noticeable for GNR in comparison with other rubber samples.

As expected, LPNR, in which soluble proteins have been removed, showed lower green strength. A similar reduction in mechanical properties was observed for MRNR. In the latter case, we suggest that the observed effect could result from two opposite trends: as the rubber particle membrane is essentially composed of phospholipids and proteins [14]; its efficient removal induces fewer branch points at chain ends. This is verified by the $\mathrm{N} \%$ (Table 5 ). Consequently this leads to a diminution of the green strength. On the other hand, the purity of MRNR after the membrane removal could promote the material strength.

The green strength profiles of GNR and MRGNR (Figure 2) reveal an upturn for raw MRGNR absent in the profile of raw GNR. This phenomenon is not fully understood, however like MRNR, we suggest that the observation results from two opposite trends. The efficient removal of the particle membrane, composed of proteins and phospholipids, is expected to reduce the branch point. On the other hand, the purity of MRGNR released from the particle core could promote material strength. Nevertheless, GNR naturally contains fewer soluble proteins and membrane attached proteins as compared with NR (Table 5). It should be noted that MRGNR had a higher molecular weight than GNR (Table 5). This can be caused by the

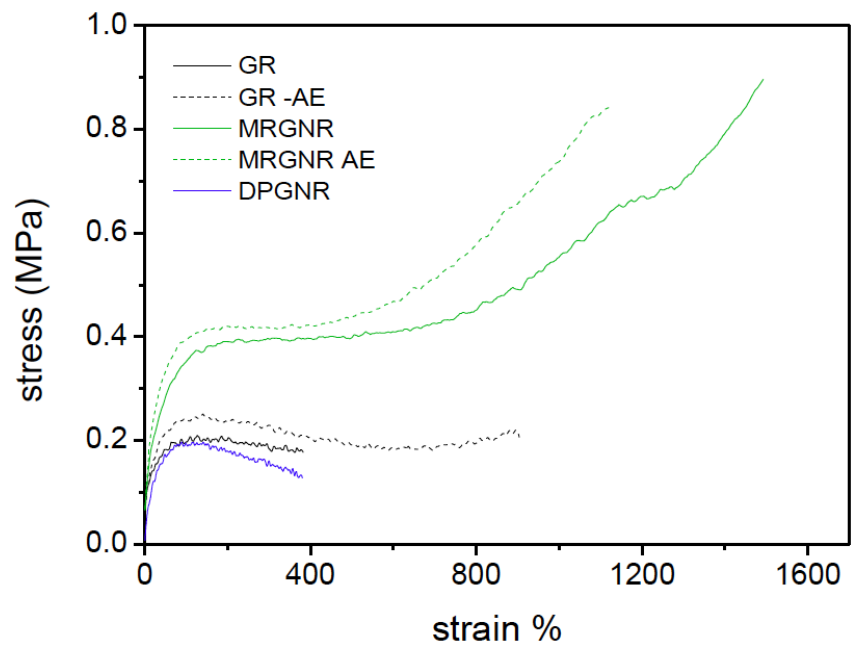

Figure 2: Green strength profile of guayule rubber (GNR), membrane removed guayule rubber (MGNR) and deproteinized guayule natural rubber (DPGNR). Raw rubber (solid line) and acetone extracted rubbers (dash lines). Each curve is the mean of 4 replicates. fatty acids in guayule resin, such as linoleic and linolenic acids, which can promote the oxidation rate of GNR.

The acetone extracted films exhibited similar properties to NR and FNR. Acetone extracted GNR had a higher elongation at break and a visible upturn in its profile. As mentioned earlier, this can be attributed to the plasticizing effect of resin and free lipids, thus their removal by acetone extraction increases the stiffness of the sample.

The values of the Young's modulus, the elongation at break and the ultimate tensile strength of the stressstrain tests are summarized in Table $\mathbf{3}$.

Table 3: Young's Modulus (Ym), Maximum Elongation (Amax) and Ultimate Tensile Strength (UTS) \pm their Corresponding se. Each Value is the Average of Six Replicates

\begin{tabular}{|c|c|c|c|}
\hline sample & Ym, KPa. & $\lambda$ max, \%. & UTS, MPa. \\
\hline \hline NR & $20 \pm 2$ & $1200 \pm 120$ & $2.10 \pm 0.20$ \\
\hline FNR & $20 \pm 2$ & $220 \pm 22$ & $0.30 \pm 0.10$ \\
\hline MRNR & $15 \pm 2$ & $1140 \pm 110$ & $1.14 \pm 0.10$ \\
\hline LPNR & $11 \pm 1$ & $1230 \pm 120$ & $1.23 \pm 0.13$ \\
\hline GNR & $19 \pm 2$ & $380 \pm 35$ & $0.18 \pm 0.02$ \\
\hline DPGNR & $18 \pm 2$ & $370 \pm 33$ & $0.13 \pm 0.02$ \\
\hline MRGNR & $15 \pm 2$ & $1400 \pm 155$ & $1.00 \pm 0.10$ \\
\hline AE-NR & $23 \pm 3$ & $1100 \pm 120$ & $2.00 \pm 0.20$ \\
\hline AE-MRGNR & $24 \pm 3$ & $1300 \pm 143$ & $1.00 \pm 0.11$ \\
\hline AEFNR & $21 \pm 2$ & $650 \pm 77$ & $0.40 \pm 0.05$ \\
\hline AE-GNR & $25 \pm 3$ & $885 \pm 89$ & $0.23 \pm 0.03$ \\
\hline
\end{tabular}

1. Young's modulus - Young's modulus values were calculated from the linear portion of the green strength plot at low elongation (maximum deformation of $3 \%$ ). Good reproducibility was observed. For raw rubber films, NR and FNR presented a higher Young's modulus than GNR and MRGNR indicating that NR and FNR were more elastic materials (see Table 3 ). The acetone extraction led to a general increase of the Young's modulus with a greater change for GNR and MRGNR than the other sample

2. Elongation at break and ultimate tensile strength - A global increase in the elongation at break and the ultimate tensile strength was observed for acetone-extracted GNR. For NR, there was a slight change of the mechanical 
properties because of its low free lipid content, therefore any change in tensile strength could be comprised in the standard error. For MRGNR, the elongation at break was reduced after acetone extraction. It is very likely that low molecular weight polyisoprene in the rubber particle affect the material strength, and in turn the ability to strain crystallize.

The mechanical properties of GNR and LPNR were also compared. GNR contains naturally low protein content, whereas in LPNR, the soluble proteins distributed in the serum fraction are discarded, leaving residual proteins surrounding the rubber particle surface. The results revealed that LPNR had higher tensile properties than GNR and this was attributed to the higher molecular weight of LPNR and its protein crosslink formation.

3. Dynamic mechanical analysis - The evolution of the storage modulus ( $\left.E^{\prime}\right)$ as a function of the temperature at a frequency of $1 \mathrm{~Hz}$ indicates that, at a temperature below the glass transition $(\mathrm{Tg})$, all rubber samples were in the glassy state, with a storage modulus constant around $2.5 \mathrm{MPa}$ (Figure 3). A sudden decrease is observed around $-60^{\circ} \mathrm{C}$, which corresponds to the relaxation phenomenon. Then the modulus reaches a plateau, which indicates the rubbery state of the material. At ambient temperature, $\left(\sim 25^{\circ} \mathrm{C}\right)$, the storage modulus of NR, GNR and MRGNR was $1.32,0.75$ and $0.7 \mathrm{MPa}$, respectively. The lower storage modulus of GNR and MRGNR were both explained by their lower molecular weight compared with NR and therefore have less chain entanglement. As the temperature increases, the modulus decreases rapidly, and the experimental setup fails to measure it. This corresponds to the irreversible flow of the material, which is correlated to the disentanglement of the polymeric chains.

The tan delta of NR, GNR and MRGNR is given in Figure 4. The tan delta of all samples shows a maximum around $-50^{\circ} \mathrm{C}$. The glass transition of NR, GNR and MRGNR was respectively $-50.3,-49.3$ and $49.9^{\circ} \mathrm{C}$.

\section{Gel Content}

Gel content is a standard property for evaluating commercial grade natural rubber as it relates to the interactions of proteins and phospholipids at the chain ends. It has been reported that these interactions govern the onset strain of SIC, as the upturn of stress occurs at a smaller strain when the gel content increases [21]. In raw rubber samples, the gel content was found to be increasing in the following sequence: GNR, MRGNR, FNR, NR, MRNR. A stress upturn was only noticeable for NR and MRNR (Figure 1), those samples with highest \% gel. As mentioned above, this is due to non-rubber components and the high molecular weight of NR. The very low gel content in GNR could explain why no upturn is visible in its stress-

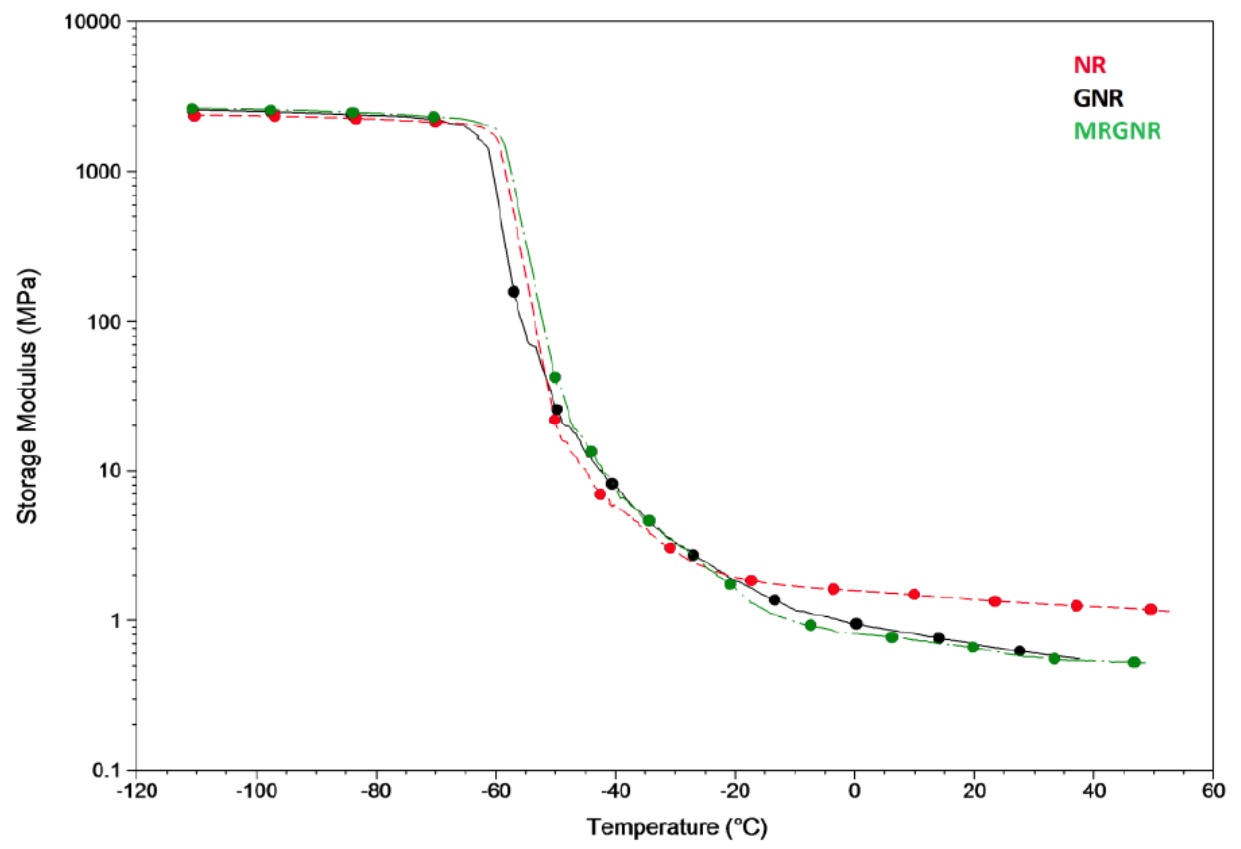

Figure 3: Evolution of the storage tensile modulus E' of NR, GNR and MRGNR as function of the temperature. 


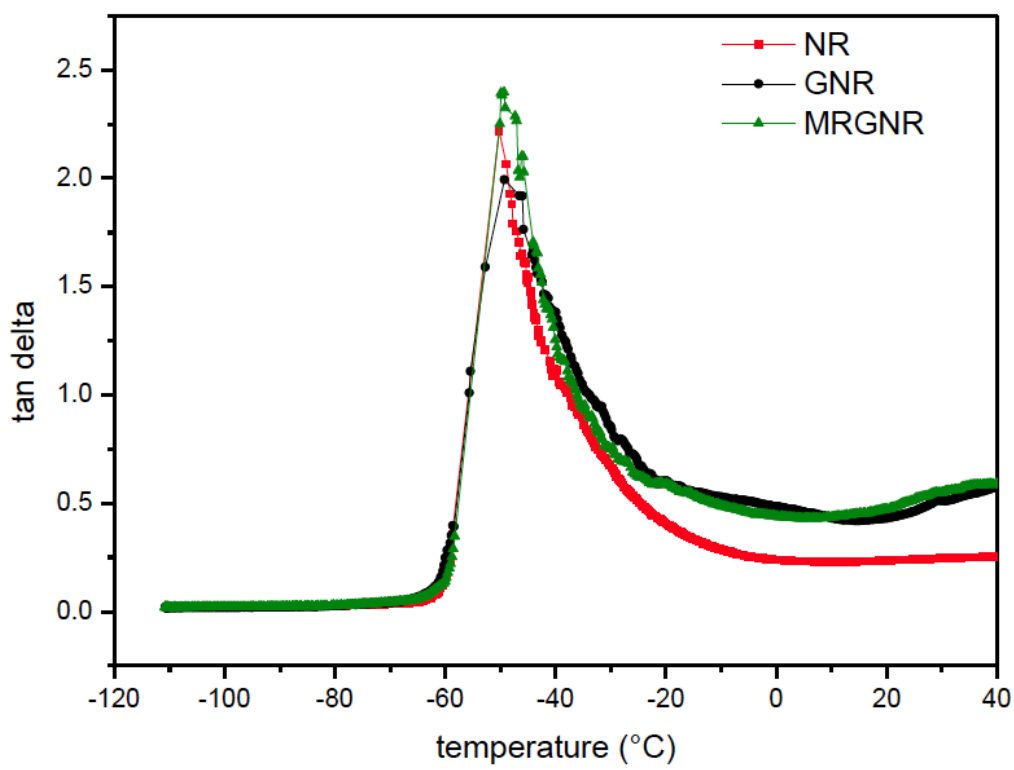

Figure 4: Tan delta of NR, GNR and MRGNR as a function of the temperature.
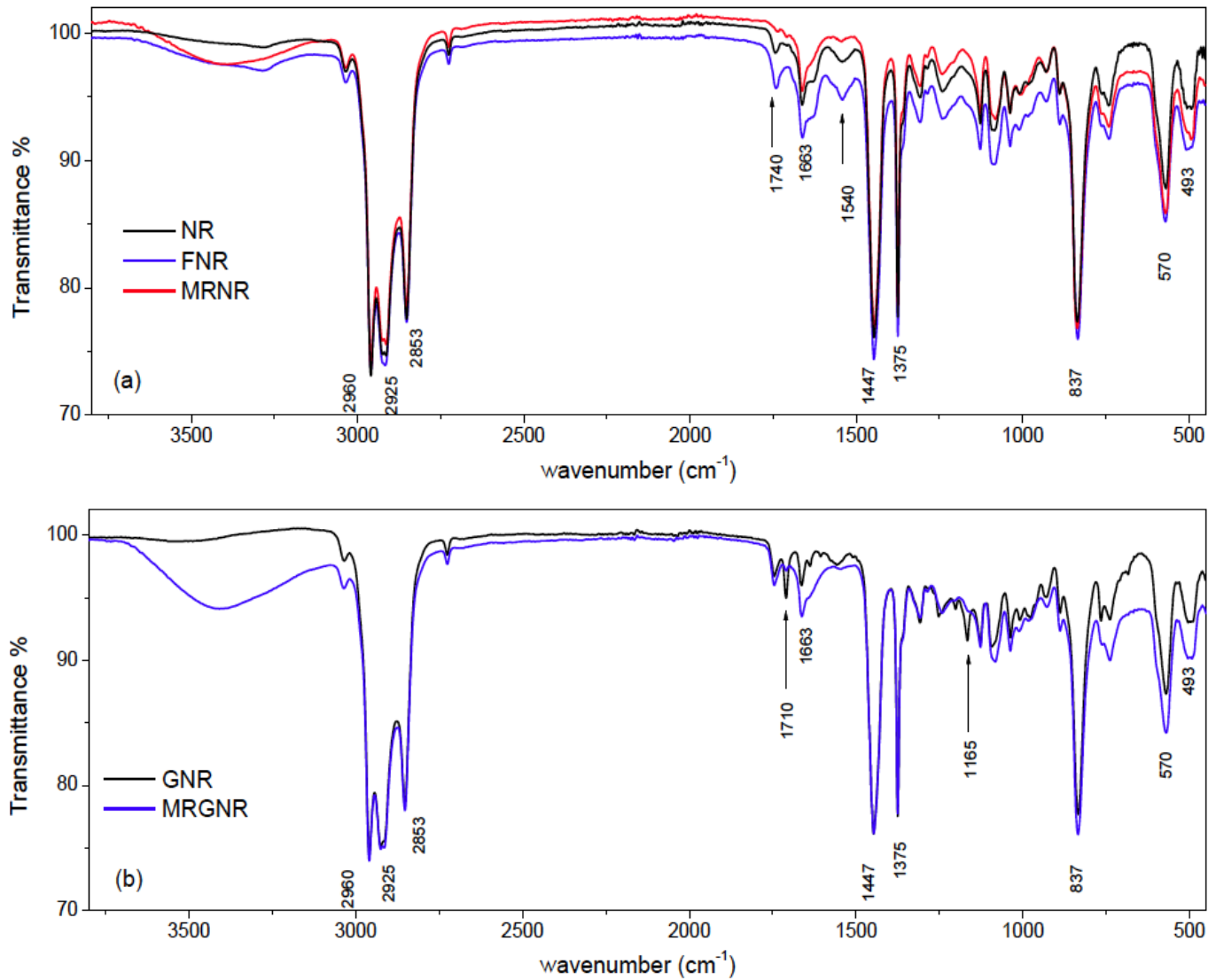

Figure 5: FTIR spectra of (a) Hevea natural rubber films and (b) guayule natural rubber films. Wavelengths are assigned as follows: 493 and $570, \mathrm{C}-\mathrm{C}$ bend cis; 837 , wagging of $=\mathrm{C}-\mathrm{H}$; $1375, \mathrm{CH}_{3}$ deformation; $1447, \mathrm{CH}_{2}$ asymmetric deformation; $1663, \mathrm{C}=\mathrm{C}$ stretching; 2853 and $2925, \mathrm{CH}_{2}$ symmetric stretching.

strain plot. FNR and MRGNR show similar gel content (and acetone soluble content) but different green strength profiles (Figures 1-2, Table 3). The nitrogen content was $0.41 \%$ and $0.1 \%$ for FNR and MRGNR, respectively, indicating a higher protein content in FNR. It is also likely that the higher molecular weight of MRGNR (Table 4) and its high purity could contribute to its strength. 
Table 4: Molecular Weight and Gel Content of Rubber Samples. Gel Contents are the Average of Three Replicates \pm se. Mw Results were Comprised within 5\% Error Margin

\begin{tabular}{|c|c|c|}
\hline Rubber type & $\mathbf{M}_{\mathbf{w}}\left(\mathbf{g ~ m o l}^{-1}\right)$ & Gel content (\%) \\
\hline \hline GNR & $6.2 \times 10^{5}$ & $8.5 \pm 4.1$ \\
\hline MRGNR & $1.2 \times 10^{6}$ & $29.0 \pm 4.4$ \\
\hline NR & $1.4 \times 10^{6}$ & $50.4 \pm 9.4$ \\
\hline FNR & $1.0 \times 10^{6}$ & $33 \pm 2.0$ \\
\hline MRNR & - & $64 \pm 9$ \\
\hline
\end{tabular}

\section{Elemental Composition}

The elemental composition of the rubber latex depends on various factors such as the clonal origin, the climatic conditions or the soil composition. However, our aim here was to identify the major elemental variations that could distinguish NR and GNR. The values obtained for NR were compared with literature data [25]. MRGNR had lower elemental components and therefore was of higher purity than its precursor, due to its method of preparation. Multivalent ions such as calcium and magnesium ions have been postulated to be involved in the ionic crosslinking of natural rubber $[5,25]$ and GNR had a slightly higher content of both calcium and magnesium than NR (Table 5). Free copper can act as a catalyst of rubber oxidation, but the ICP analysis performed in this study does not differentiate between complexed copper and free copper. Sulfur content is mostly derived from proteins, arising from amino acids such as cysteine or methionine. A higher sulfur content was observed for GNR than NR which might seem at first in contradiction with the explanation above. However the lower protein content of GNR has been demonstrated in the literature $[22,23]$, and is confirmed here with the $N \%$. NR is tapped from the Hevea tree while GNR is extracted from guayule bark; it is therefore possible to coextract other components during the guayule rubber latex preparation. During the preparation of FNR, the high molecular weight polymer is sieved, leaving the FNR with insoluble minerals. This explains the general higher ash content in FNR.

\section{Infrared Analysis of Rubber Films}

Rubber films were analyzed by attenuated total reflectance. As the main component of the natural rubber films is cis-1,4 polyisoprene, common peaks were found in NR, FNR, MRNR, GNR and MRGNR.

NR and FNR had similar infrared spectra while in MRNR the peaks 1740 and $1540 \mathrm{~cm}^{-1}$ were not observed. The peak at $1540 \mathrm{~cm}^{-1}$ is due to acid amides of Hevea natural rubber proteins [28]. Similarly the presence of phospholipids or proteins could induce the formation of peak at $1740 \mathrm{~cm}^{-1}$, thus these results confirm the efficient particle membrane removal in MRNR. The comparison of GNR and MRGNR infrared spectra reveals the presence of peaks at $1710 \mathrm{~cm}^{-1}$

Table 5: Quantification of Major Elements in Rubber Samples ( $\mu \mathrm{g} / \mathrm{g})$. The Results are the Average of Two Replicates and are within 5\% Error Margin

\begin{tabular}{|c|c|c|c|c|c|}
\hline Composition $(\mu \mathrm{g} / \mathrm{g})$ & NR & FNR & MRNR & GNR & $\begin{array}{c}\text { MRGNR } \\
\text { R }\end{array}$ \\
\hline $\mathrm{N}$ & 4500 & 41000 & 1500 & 500 & 1000 \\
\hline $\mathrm{K}$ & 1587 & 1323 & 1147 & 2973 & 161 \\
\hline $\mathrm{Ca}$ & 78 & 193 & 108 & 132 & 64 \\
\hline$S$ & 278 & 322 & 145 & 738 & 247 \\
\hline $\mathrm{Al}$ & 39 & 84 & 15 & 40 & 23 \\
\hline B & 10 & 20 & 10 & 9.9 & 9.5 \\
\hline $\mathrm{Cu}$ & 4.4 & 7.5 & 1 & 0.5 & 0.6 \\
\hline $\mathrm{Na}$ & 76.1 & 326 & 30 & 533 & 30 \\
\hline $\mathrm{Zn}$ & 224 & 15 & 25 & 2.4 & 0.1 \\
\hline
\end{tabular}


and $1166 \mathrm{~cm}^{-1}$ in GNR which are not detected in MRGNR. The peak at $1710 \mathrm{~cm}^{-1}$ is attributed to $C=0$ stretching mode which could derive from the high fatty acids content in guayule resin (linoleic acid) or oxidation products. The peak at $1166 \mathrm{~cm}^{-1}$ is attributed to the $\mathrm{C}-\mathrm{O}$ bond stretching characterizing the presence of carboxylic acids. Dos Santos. et al. found that the intensity of the peak at $1166 \mathrm{~cm}^{-1}$ is increased upon UV exposure of polyisoprene, indicating the oxidation of the rubber. The broad peak ranging from 3200 to 3500 $\mathrm{cm}^{-1}$ is caused by the absorption of hydroxyl group due to the oxidative degradation of the polymer chains.

\section{CONCLUSIONS}

In this work, the mechanical properties of uncompounded natural rubber have been studied and the effects of non-rubber constituents of GNR and NR were analyzed. Among the tested samples, GNR had the highest neutral lipid and resin content. These act like plasticizers and explain the softness of the material. After acetone extraction, a general increase of the ultimate tensile strength was observed. FNR showed similar green strength to GNR, despite its higher protein content. This demonstrates the importance of the molecular weight of polymer chains. Free lipids have a drastic plasticizing effect; for this reason their extraction greatly improves the green strength of guayule natural rubber.

The effect of rubber particle membrane removal was investigated by the preparation of MRNR and MRGNR and its comparison with control rubbers. The efficient membrane removal was confirmed both by lower nitrogen content and by ATR analysis. A stressstrain upturn was observed in green strength for both rubber samples. This phenomenon is not fully understood and was more pronounced in MRGNR than in MRNR. We propose that this phenomenon may result from two opposite effects: the removal of the rubber particle membrane reducing the rubber natural network, while the purity of MRNR and MRGNR and the low molecular weight polyisoprene released from the particle core promotes the material strength.

\section{REFERENCES}

[1] Amnuaypornsri S, Sakdapipanich J, Tanaka Y. Green strength of natural rubber: the origin of the stress-strain behavior of natural rubber. J Appl Polym Sci 2009; 111: 2127-33.

http://dx.doi.org/10.1002/app.29226

[2] Ikeda $\mathrm{Y}$, Preeyanuch J, Ohashi $\mathrm{T}$, et al. Strain-induced crystallization behaviour of natural rubbers from guayule and rubber dandelion revealed by simultaneous time-resolved
WAXD/tensile measurements: indispensable function for sustainable resources. RSC Adv 2016; 6: 95601-10. http://dx.doi.org/10.1039/C6RA22455E

[3] Tanaka Y, Kawahara S, Tangpakdee J. Structural characterization of natural rubber. Kaut Gummi Kunstst 1997; 50: 6-11.

[4] Chemistry and Physics of Rubber-like Substance, MacLaren and Sons: London, U.K., 1963.

[5] Amnuaypornsri S, Tarachiwin L, Sakdapipanich JT. Character of long-chain branching in highly purified natural rubber. J Appl Polym Sci 2009; 115: 3645-50. http://dx.doi.org/10.1002/app.31419

[6] Thuong NT, Yamamoto O, Nghia PT, Cornish K, Kawahara S. Effect of naturally occurring crosslinking junctions on green strength of natural rubber. Polym Adv Technol 2016. http://dx.doi.org/10.1002/pat.3887

[7] Trabelsi S, Albouy P-A, Rault J. Stress-induced crystallization properties of natural and synthetic CISpolyisoprene. Rubber Chem Technol 2004; 77: 303-16. http://dx.doi.org/10.5254/1.3547825

[8] Shimomura Y, White JL, Spuriell JE. A comparative study of stress-induced crystallization of guayule, hevea, and synthetic polyisoprenes. J Appl Polym Sci 1982; 27: 3553-67. http://dx.doi.org/10.1002/app.1982.070270929

[9] Cornish K, Wood DF, Windle JJ. Rubber particles from four different species, examined by transmission electron microscopy and electron-paramagnetic-resonance spin labeling, are found to consist of a homogeneous rubber core enclosed by a contiguous, monolayer biomembrane. Planta 1999; 210: 85-96. http://dx.doi.org/10.1007/s004250050657

[10] Pichayakorn W, Suksaeree J, Boonme P, Taweepreda W, Ritthidej GC. Preparation of deproteinized natural rubber latex and properties of films formed by itself and several adhesive polymer blends. Ind Eng Chem Res 2012; 51: 13393.

http://dx.doi.org/10.1021/ie301985y

[11] Protein (crude) in animal feed combustion method (Dumas method), Method 990.03. AOAC Official Methods of Analysis, JAOAC, 1968; 51: 766.

[12] Sommers LE, Nelson DW. Determination of Total Phosphorus in Soils: A Rapid Perchloric Acid Digestion Procedure. In Soil Science Society of America Proceedings: Madison, WI, USA, 1972; 36: 902. http://dx.doi.org/10.2136/sssaj1972.03615995003600060020 $\underline{x}$

[13] Hossner, L.R. Dissolution for total elemental analysis. In Methods of Soil Analysis, Part 3-Chemical Methods. Soil Science Society of America: Madison, WI, USA. 1996; 49.

[14] Lotti C, Moreno RMB, Gonçalves P de S, Bhattacharya S, Mattoso LHC. Extension rheology of raw natural rubber from new clones of Hevea brasiliensis. Polym Eng Sci 2012; 52: 139-48.

http://dx.doi.org/10.1002/pen.22056

[15] Sakdapipanich JT. Structural characterization of natural rubber based on recent evidence from selective enzymatic treatments. J Biosci Bioeng 2007; 103: 287-92. http://dx.doi.org/10.1263/jbb.103.287

[16] Karino T, Ikeda Y, Yasuda Y, Kohjiya S, Shibayama M. Nonuniformity in natural rubber as revealed by small-angle neutron scattering, small-angle X-ray scattering, and atomic force microscopy. Biomacromolecules 2007; 8: 693-9. http://dx.doi.org/10.1021/bm060983d

[17] Nawamawat K, Sakdapipanich JT, Ho CC. Effect of deproteinized methods on the proteins and properties of natural rubber latex during storage. Macromol Symp 2010; 288: 95-103.

http://dx.doi.org/10.1002/masy.201050212 
[18] Oh J, Yoo YH, Yoo I-S, Huh YI, Chaki TK, Nah C. Effect of plasticizer and curing system on freezing resistance of rubbers. J Appl Polym Sci 2014; 131: 39795. http://dx.doi.org/10.1002/app.39795

[19] Banker GS. Film coating theory and practice. J Pharm Sci 1966; 55: 81-9. http://dx.doi.org/10.1002/jps.2600550118

[20] Rezende CA, Bragança FC, Doi TR, Lee LT, Galembeck F, Boué F. Natural rubber-clay nanocomposites: Mechanical and structural properties. Polymer $2010 ; 51: 3644-52$. http://dx.doi.org/10.1016/j.polymer.2010.06.026

[21] Che J, Burger C, Toki S, et al. Crystal and crystallites structure of natural rubber and peroxide-vulcanized natural rubber by a two-dimensional wide-angle X-ray diffraction simulation method. II. Strain-induced crystallization versus temperature-induced crystallization. Macromolecules 2013; 46: 9712-21. http://dx.doi.org/10.1021/ma401812s

[22] Nimpaiboon A, Amnuaypornsri S, Sakdapipanich J. Influence of gel content on the physical properties of unfilled and carbon black filled natural rubber vulcanizates. Polym Test 2013; 32: 1135-44.

http://dx.doi.org/10.1016/j.polymertesting.2013.07.003
[23] Cornish K. Rubber Science 2012; 25: 139.

[24] McMahan C, Kostyal D, Lhamo D, Cornish K. Protein influences Guayule and Hevea natural rubber sol and gel. J Appl Polym Sci 2015; 132: 42051. http://dx.doi.org/10.1002/app.42051

[25] Kawahara S, Kakubo T, Nishiyama N, Tanaka $Y$, Isono $Y$, Sakdapipanich J. Crystallization behaviour and strength of natural rubber: skim rubber, deproteinized natural rubber and pale crepe. J Appl Polym Sci 2000; 78: 1510-16. http://dx.doi.org/10.1002/10974628(20001121)78:8<1510::AID-APP70>3.0.CO;2-4

[26] Thomas S, Chan CH, Pothen LA, Rarjisha KR, Maria HJ. Natural rubber materials: blends and IPNs. RSC Polymer Chemistry Series. 2013.

[27] Siler DJ, Cornish K. Hypoallergenicity of guayule rubber particle proteins compared to Hevea latex proteins. Ind Crops Prod 1994; 2 : 307-13.

http://dx.doi.org/10.1016/0926-6690(94)90122-8

[28] Dos Santos KAM, Suarez PAZ, Rubim JC. Photodegradation of synthetic and natural polyisoprenes at specific UV radiations. Polym Degrad Stabil 2005; 90: 34-43. http://dx.doi.org/10.1016/j.polymdegradstab.2005.01.038

[29] Liao SQ, She XD, Li SD, et al. J Polym Mater 2010; 27 : 69.

Received on 11-09-2016

DOI: http://dx.doi.org/10.6000/1929-5995.2016.05.03.1

(C) 2016 Monadjemi et al.; Licensee Lifescience Global.

This is an open access article licensed under the terms of the Creative Commons Attribution Non-Commercial License (http://creativecommons.org/licenses/by-nc/3.0/) which permits unrestricted, non-commercial use, distribution and reproduction in any medium, provided the work is properly cited. 